Advancements in Instrumentation

\title{
Development of a Simple Column Electrode for Sensitive and Rapid Coulometry
}

\author{
Megumi Kasuno, ${ }^{* * * \dagger}$ Katsuki Morishima,* Takayuki Matsushita,* and Sorin Kinara*** \\ *Department of Materials Chemistry, Faculty of Science and Technology, Ryukoku University, \\ Seta, Otsu 520-2194, Japan \\ **Department of Materials Chemistry, Innovative Materials and Processing Research Center, \\ Ryukoku University, Seta, Otsu 520-2194, Japan \\ ***Kyoto Institute for Interesting Chemistry, 40-5 Sakuradani Kamikazan, Yamashina, Kyoto 607-8466, Japan
}

\begin{abstract}
A simple column electrode, S-CE, with a glassy carbon fibers working electrode stuffed into a Teflon tube was developed. The current-potential curves for the reductions of $\left[\mathrm{Fe}(\mathrm{CN})_{6}\right]^{3-}$ and $\mathrm{Fe}^{3+}$ observed at the S-CE were analyzed based on a theory for those at an ordinary column electrode. A quantitative electrolysis was performed at the S-CE rapidly within $20 \mathrm{~s}$. An accurate and precise coulometric determination could be attained at the S-CE even with a fairly dilute solution. For example, coulometric reductions of $5 \times 10^{-5}$ and $5 \times 10^{-6} \mathrm{M} \mathrm{Fe}^{3+}$ were attained with efficiencies $(n=5)$ of $99.7 \pm 0.2$ and $101.9 \pm 1.1 \%$, respectively.
\end{abstract}

(Received April 28, 2009; Accepted June 2, 2009; Published July 10, 2009)

\section{Introduction}

Coulometry is an important branch of analytical chemistry because of its unique advantage as an absolute method.

The determination by coulometry has been attained with an accuracy of more than $99 \%$ and a precision greater than $0.1 \%$ when the concentration of the redox species of interest is higher than $10^{-3} \mathrm{M}\left(\mathrm{M}=\mathrm{mol} \mathrm{dm}^{-3}\right) \mathrm{d}^{1,2}$ However, when the concentration is decreased, the accurate and precise determination becomes difficult because the background current is large compared to the signal current, causing a serious error in a background correction. Since the error is more serious when the period required to achieve quantitative electrolysis is longer, rapid electrolysis is essential for an accurate and precise coulometric determination. Rapid electrolysis can be attained when the surface area of the working electrode, $A$, is large compared to the volume of the sample solution, $V$, and the thickness of the diffusion layer at the working electrode surface, $\delta$, is small. ${ }^{3-5}$

One of the methods expected to be useful for rapid quantitative electrolysis is a flow-through method by using a thin-layer cell ${ }^{6-9}$ and a column electrode ${ }^{10-15}$ in which the ratio $A / V$ is large and $\delta$ is made thin by flowing a solution. Here, the thin layer cell with a thin solution path has been prepared by using a spacer, or etching working electrodes, such as a glassy carbon, GC, and plate. A column electrode has been prepared by using a working electrode of GC grains, ${ }^{10-12}$ platinum grains,,${ }^{13}$ GC fibers,${ }^{14,15}$ or other materials stuffed into a cylindrical porous electrolytic diaphragm, such as a porous glass cylinder ${ }^{10,14}$ or ion exchanger tube. ${ }^{12,15}$

The flow-through method involves the following difficulties from the viewpoint of accurate and precise coulometric

† To whom correspondence should be addressed.

E-mail:kasuno@rins.ryukoku.ac.jp determination: 1) It is not easy to attain an electrolysis efficiency, $\varepsilon$, higher than $99 \%$ by using a thin-layer cell, since the preparation of a solution path that is very thin (e.g., thinner than $20 \mu \mathrm{m}$ ) and fairly long (e.g., longer than $10 \mathrm{~cm}$ ) is technically difficult. The precision observed by the thin-layer cell is not better than $1 \%$, although a discussion on the precision has scarcely been made so far; ${ }^{6-9}$ 2) Though an $\varepsilon$ better than $99 \%$ could be attained by using a column electrode, since the solution path in the column electrode is thin enough $(e . g ., 10 \mu \mathrm{m}),{ }^{10}$ it is not easy to perform the determination with a precision better than $1 \%$. The reason for the poor precision is attributable to that the amount of the working electrode material stuffed in the electrolytic diaphragm cylinder in a column electrode is unnecessarily large, and the charging current at the electrode surface not participating in the electrolysis causes a large background current; 3) Another reason for the poor precision with the thin-layer cell or the column electrode is that the determination by the homogeneous solution flow method (performed by forcing to flow a solution containing the species of interest and a supporting electrolyte, SE, through the cell) has been carried out based on the flow-rate, $f$, of the sample solution and the limiting current, $I_{\mathrm{l}}$, in the current-potential, $I-E$, curve. It is not easy to precisely measure $f$ and $I_{1}$ which fluctuates depending on $f ; 4$ ) The other difficulty of the column electrode is that the structure of the electrode is rather complex and not easy to prepare without circumstance and on the cheap.

In the present work, a column electrode with a very simple structure (hereinafter abbreviated as "S-CE") was developed by using GC fibers stuffed into a Teflon tube as the working electrode in order to overcome the above-described difficulties 2) to 4). The unnecessary surface area of the working electrode was minimized in the S-CE. The performance of the S-CE was evaluated based on the coulomb number, $Q$, obtained by electrolysis for a definite time, $t$, and the volume of the sample solution flowing through the S-CE, $U$, during $t$ instead of $I_{1}$ and 
(i)

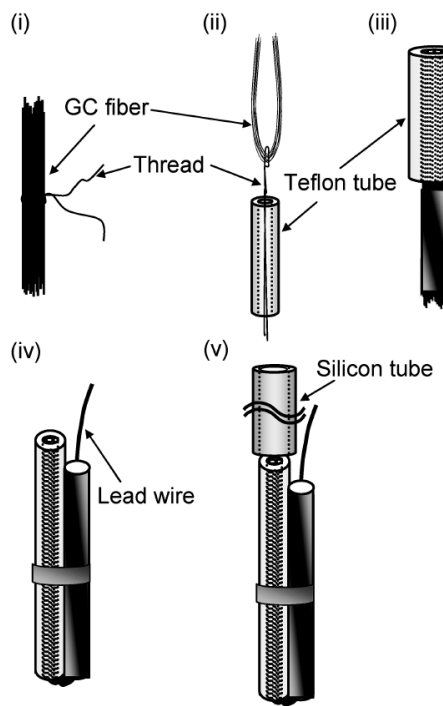

Fig. 1 Procedure for the preparation of a simple column electrode, S-CE.

$f$, respectively. The accuracy and precision of the flow injection method (performed by injecting a definite volume of the sample solution into the stream of a solution containing only the SE) were also investigated.

\section{Experimental}

\section{Fabrication of simple column electrode, $S-C E$}

Figure 1 illustrates the procedure for fabricating of the S-CE. The working electrode of the S-CE is a bundle of GC fibers ( $c a$. $10 \mu \mathrm{m}$ in average diameter, Tokai Carbon, GC-20) tightly inserted into a Teflon tube (commercially available as a piping material in liquid chromatography: Nichias Co.) with the aid of a guiding of a thread. The Teflon tube has an i.d. of $1.0 \mathrm{~mm}$, an o.d. of $2.0 \mathrm{~mm}$, and a length, $l$, of $50 \mathrm{~mm}$, unless otherwise mentioned. The portion of the GC fibers sticking out from the end of the tube is firmly wound with a non-electroconductive tape (IWAKI Co., NOVIX-2-10), and connected to a potentiostat through a lead wire. The other end of the Teflon tube is connected to a silicon tube through which the sample solution is introduced to the S-CE.

\section{Electrochemical measurement}

The electrolysis was carried out by using a silver/silver chloride electrode with saturated $\mathrm{KCl}, \mathrm{SSE}$, and a platinum net as the reference and counter electrodes, respectively.

A coulometric determination by a homogeneous solution flow method was performed by forcing a sample solution to flow through the narrow channels among the GC fibers (abbreviated as "channels") with the aid of a plunger pump (Eyela, Tokyo Rikakikai Co., Model SP12-12) at a constant $f$. The $U$ flowing through the tube during electrolysis was precisely measured by weighing the decrease in the sample solution (see, Fig. S1).

The flow injection method was performed by injecting a definite volume $(54.75 \pm 0.01 \mu \mathrm{L})$ of sample solution into the stream of a background solution with a sample injector for liquid chromatography (FLOM Co., Model VI-13). Here, the volume of the injector was determined based on $Q$ obtained by 20 repeated electrolysis procedures of a $\mathrm{Fe}^{3+}$ standard solution (prepared by dissolving an iron wire of $99.999 \%$ purity; see, Chemicals) injected with the aid of an injector to the S-CE. The background solution was forced to flow with the aid of a syringe pump (KD Scientific Co., Model KDS3100) at a constant $f$.

The measurement of the $I-E$ curve at the S-CE was performed by forcing a sample solution to flow through the "channels" with the aid of a syringe pump at a constant $f$, and scanning $E$ at a rate, $v$, of $0.0002 \mathrm{~V} \mathrm{~s}^{-1}$.

A pretreatment of the $\mathrm{GC}$ fiber working electrode was carried

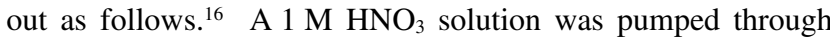
the "channels" in the Teflon tube at an $f$ of $0.2 \mathrm{~mL} \mathrm{~min}^{-1}$, and the $E$ applied to the working electrode was scanned cyclically 10 times between -1.0 and $+1.8 \mathrm{~V}$ versus SSE at $v$ of $0.010 \mathrm{~V} \mathrm{~s}^{-1}$. $E$ was then kept at $+1.8 \mathrm{~V}$ for $30 \mathrm{~min}$.

A potentiostat equipped with a positive feedback circuit for IR-drop compensation (Hokuto Denko Co., Model HA1010mM1A), the function generator (Hokuto Denko Co., Model HB-111), an X-Y recorder (Riken Denshi Co., Model F-35Fm), and coulometer (Hokuto Denko Co., Model HF-201) were used for voltammetric or coulometric measurements.

All electrochemical measurements were carried out at $25 \pm 1^{\circ} \mathrm{C}$.

\section{Chemicals}

A stock solution of $\left[\mathrm{Fe}(\mathrm{CN})_{6}\right]^{3-}(0.1 \mathrm{M})$ was prepared by dissolving potassium hexacyanoferrate(III) of $99 \%$ purity (Wako Chemical Co.) in $1 \mathrm{M} \mathrm{KCl}$.

The stock solution of $\mathrm{Fe}^{3+}(0.1 \mathrm{M}$, factor, $f=1.006)$ was prepared by dissolving a high-purity iron wire $(99.999 \%$, Nilaco Co., No. 16558/67750) in $3 \mathrm{M}$ hydrochloric acid, adding concentrated nitric acid, and evaporating the solution to dryness. The process was repeated once more, and then the residue was dissolved in $1 \mathrm{M} \mathrm{HCl.}{ }^{17}$

All other chemicals used in the present work were of reagent grade.

\section{Results and Discussion}

\section{Electrolytic performance of the developed S-CE}

The electrode reactions at the $\mathrm{S}-\mathrm{CE}$ were investigated by adopting $\left[\mathrm{Fe}(\mathrm{CN})_{6}\right]^{3-}$ in $1 \mathrm{M} \mathrm{KCl}$ and $\mathrm{Fe}^{3+}$ in $1 \mathrm{M} \mathrm{H}_{2} \mathrm{SO}_{4}$; these reduction reactions at the $\mathrm{GC}$ electrode have been reported ${ }^{14,18}$ to be reversible and quasi-reversible to irreversible, respectively.

The $I-E$ curve for the reduction of $\left[\mathrm{Fe}(\mathrm{CN})_{6}\right]^{3-}$ or $\mathrm{Fe}^{3+}$ was recorded by passing a solution containing $5 \times 10^{-4} \mathrm{M}\left[\mathrm{Fe}(\mathrm{CN})_{6}\right]^{3-}$ and $1 \mathrm{M} \mathrm{KCl}$ or $5 \times 10^{-4} \mathrm{M} \mathrm{Fe}^{3+}$ and $1 \mathrm{M} \mathrm{H}_{2} \mathrm{SO}_{4}$, respectively, through the $\mathrm{S}-\mathrm{CE}$ at an $f$ of $0.1 \mathrm{~mL} \mathrm{~min}^{-1}$ and scanning $E$ at a $v$ of $0.0002 \mathrm{~V} \mathrm{~s}^{-1}$. The $I-E$ curve is shown as curve 1 or 2 in Fig. 2 after correcting for the background current (curve $1^{\prime}$ or $2^{\prime}$ in Fig. 2) observed in the absence of $\left[\mathrm{Fe}(\mathrm{CN})_{6}\right]^{3-}$ or $\mathrm{Fe}^{3+}$. Here, it is worth to note that the background current obtained at the S-CE was considerably small and about $1 / 30$ of that at the ordinary column electrode. ${ }^{10,14}$

The $I_{1}$ of the negative currents were close to those theoretically expected, $I_{\mathrm{lt}}$, for quantitative electrolysis (i.e., $\varepsilon=100 \%$ ) at the flow-through electrolytic cell: ${ }^{10,19}$

$$
I_{\mathrm{lt}}=n F c f,
$$

where $n$ and $c$ are the number of electrons involved in the electrode reaction and concentration of the redox species of interest, respectively, and $F$ is the Faraday constant. The $I_{1}$ observed by 5 repeated measurements $(n=5)$ for the reduction of $\left[\mathrm{Fe}(\mathrm{CN})_{6}\right]^{3-}$ was $101 \pm 5$ or $100 \pm 3 \%$ of $I_{\text {lt }}$ when the 


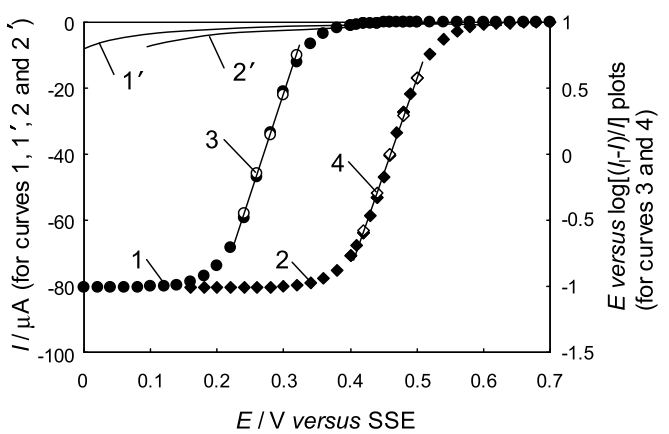

Fig. 2 Current-potential curve for the reduction of $5 \times 10^{-4} \mathrm{M}$ $\left[\mathrm{Fe}(\mathrm{CN})_{6}\right]^{3-}($ curve 1$)$ or $5 \times 10^{-4} \mathrm{M} \mathrm{Fe}^{3+}($ curve 2$)$ at the S-CE. Curve $1^{\prime}$ or $2^{\prime}$ is the background current for curve 1 or 2, respectively. Plot 3 or 4 is the $E$ versus $\log \left[\left(I_{1}-I\right) / I\right]$ plot for curve 1 or 2, respectively. Supporting electrolytes, $1 \mathrm{M} \mathrm{KCl}$ (for curves 1 and $1^{\prime}$ ) or $1 \mathrm{M} \mathrm{H}_{2} \mathrm{SO}_{4}$ (for curves 2 and $2^{\prime}$ ); $f, 0.1 \mathrm{~mL} \mathrm{~min}^{-1} ; v, 0.0002 \mathrm{~V} \mathrm{~s}^{-1} ; l, 50 \mathrm{~mm} ; N_{\text {fiber }}$, 4000 .

concentration of $\left[\mathrm{Fe}(\mathrm{CN})_{6}\right]^{3-}, c_{\left[\mathrm{Fe}\left(\mathrm{CN}_{6}\right)^{3}\right]}$, was $5 \times 10^{-5}$ or $5 \times 10^{-4}$ $\mathrm{M}$, respectively and $f$ was $0.1 \mathrm{~mL} \mathrm{~min}^{-1}$. $I_{1}$ was $102 \pm 5,100 \pm$ 3 or $101 \pm 3 \%$ of $I_{\mathrm{lt}}$ when $f$ was $0.05,0.2$ or $0.5 \mathrm{~mL} \mathrm{~min}^{-1}$ and $c_{\left[\mathrm{Fe}\left(\mathrm{CN}_{6}\right)^{3}\right]}$ was $5 \times 10^{-4} \mathrm{M}$. When $\mathrm{Fe}^{3+}$ was investigated instead of $\left[\mathrm{Fe}(\mathrm{CN})_{6}\right]^{3-}$, the effects of the concentration of $\mathrm{Fe}^{3+}, c_{\mathrm{Fe}^{3+}}$, and $f$ were similar to those observed with $\left[\mathrm{Fe}(\mathrm{CN})_{6}\right]^{3-}$.

The $E$ versus $\log \left[\left(I_{1}-I\right) / I\right]$ plots for the waves of curves 1 and 2 in Fig. 2 according to Eq. (2) proposed to express the $I-E$ curve for the reversible reduction at a column electrode ${ }^{14}$ gave straight lines with slopes of $0.060 \pm 0.002$ and $0.061 \pm 0.002$, respectively (plots 3 and 4 in Fig. 2):

$$
E=E_{1 / 2}-\frac{2.303 R T}{n F} \log \left(\frac{I_{1}-I}{I}\right)
$$

where $R$ and $T$ are the gas constant and temperature, respectively. The half-wave potential, $E_{1 / 2}$, is given as ${ }^{10}$

$$
E_{1 / 2}=E^{0}-\frac{2.303 R T}{n F} \log \left(\frac{D_{\mathrm{O}}}{D_{\mathrm{R}}}\right)^{2 / 3},
$$

where $E^{0}$ is the formal electrode potential. $D_{\mathrm{O}}$ and $D_{\mathrm{R}}$ are the diffusion coefficients of the oxidant and reductant, respectively.

The $E_{1 / 2}$ value of the negative current wave for the reduction of $\left[\mathrm{Fe}(\mathrm{CN})_{6}\right]^{3-}$ or $\mathrm{Fe}^{3+}$ was +0.26 or $+0.46 \mathrm{~V}$ versus SSE. The slope of $E$ versus $\log \left[\left(I_{1}-I\right) / I\right]$ plot and $E_{1 / 2}$ for the reduction of $\left[\mathrm{Fe}(\mathrm{CN})_{6}\right]^{3-}$ observed by changing $f$ were identical with those observed at $f=0.1 \mathrm{~mL} \mathrm{~min}^{-1}$ as long as $f$ was less than $0.5 \mathrm{~mL} \mathrm{~min}^{-1}$, and were $0.064 \mathrm{~V}$ and $+0.25 \mathrm{~V}$ versus SSE when $f$ was $0.8 \mathrm{~mL} \mathrm{~min}^{-1}$, which indicates that the reduction of $\left[\mathrm{Fe}(\mathrm{CN})_{6}\right]^{3-}$ at the S-CE shows a reversible character when $f$ is less than $0.5 \mathrm{~mL} \mathrm{~min}^{-1}$. Although the slope of E versus $\log \left[\left(I_{1}-\right.\right.$ $I) / I$ ] plot and $E_{1 / 2}$ for the reduction of $\mathrm{Fe}^{3+}$ observed at $f=$ $0.2 \mathrm{~mL} \mathrm{~min}^{-1}$ were identical to those observed at $f=0.1 \mathrm{~mL} \mathrm{~min}^{-1}$, they shifted when $f$ was larger than $0.3 \mathrm{~mL} \mathrm{~min}^{-1}$, as shown in Fig. 3. The slope was 0.067 or $0.076 \mathrm{~V}$ and $E_{1 / 2}$ was 0.45 or $0.43 \mathrm{~V}$ versus $\mathrm{SSE}$ when $f$ was 0.4 or $0.7 \mathrm{~mL} \mathrm{~min}^{-1}$, respectively. These shifts indicate that the $I-E$ curve for the reduction of $\mathrm{Fe}^{3+}$ shows a reversible character when $f$ is less than $0.2 \mathrm{~mL} \mathrm{~min}^{-1}$, and a quasi-reversible character when $f$ is larger than $0.3 \mathrm{~mL} \mathrm{~min}^{-1}$.

The results described above demonstrate that the electrode

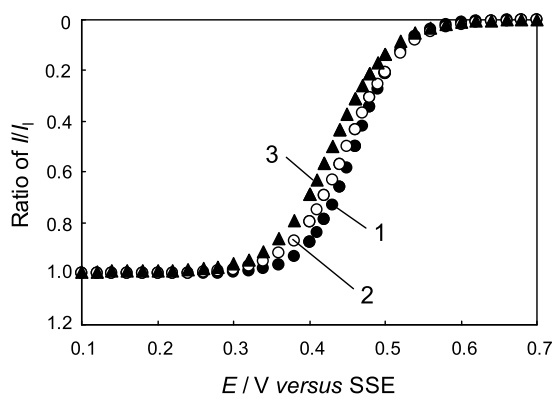

Fig. 3 Current-potential curves for the reduction of $5 \times 10^{-4} \mathrm{M} \mathrm{Fe}^{3+}$ at the S-CE. $f: 0.1$ and 0.2 (curve 1), 0.4 (curve 2) or 0.7 (curve 3) $\mathrm{mL} \mathrm{min}^{-1}$. The ordinate indicates the relative value of $I$ to $I_{1}\left(I / I_{1}\right)$. Supporting electrolyte, $1 \mathrm{M} \mathrm{H}_{2} \mathrm{SO}_{4} ; v, 0.0002 \mathrm{~V} \mathrm{~s}^{-1} ; l, 50 \mathrm{~mm} ; N_{\text {fiber, }}$, 4000 .

reactions observed at the developed S-CE are identical to those expected theoretically, ${ }^{14}$ even though the structure of the S-CE is very simple.

Accuracy and precision of coulometric determination using the $S-C E$ under various conditions

The applicability of the S-CE to the accurate and precise coulometric determination was examined by adopting the reduction of $\mathrm{Fe}^{3+}$ to $\mathrm{Fe}^{2+}(n=1)$ in $1 \mathrm{M} \mathrm{H}_{2} \mathrm{SO}_{4}$. In this investigation, the accuracy and precision were evaluated based on $\varepsilon$ calculated from a $Q$ value obtained experimentally by electrolysis for a definite $t$ at $E$ available for $I_{1}$ followed by a correction for the background value observed in the absence of $\mathrm{Fe}^{3+}, Q_{\text {ex }}$. Here, the theoretical value of $Q, Q_{\mathrm{t}}$, can be expressed by integrating $I_{\mathrm{lt}}$ (Eq. (1)) with the time from 0 to $t$;

$$
Q_{\mathrm{t}}=\int I_{\mathrm{lt}} \mathrm{d} t=F c_{\mathrm{Fe}^{3+}} \int \mathrm{f} \mathrm{d} .
$$

The integration of $f$ gives the $U$ flowing through the S-CE during electrolysis; hence, using $U, Q_{\mathrm{t}}$ is given as

$$
Q_{\mathrm{t}}=F c_{\mathrm{Fe}^{3+}} U \text {. }
$$

Therefore, the $\varepsilon(\%)$ can be expressed as

$$
\begin{aligned}
\varepsilon & =100\left(Q_{\mathrm{ex}} / Q_{\mathrm{t}}\right) \\
& =100\left(Q_{\mathrm{ex}} / F c_{\mathrm{Fe}^{3+}} U\right) .
\end{aligned}
$$

Though both $I_{1}$ and $Q_{\mathrm{ex}}$ can be used for the coulometric determination of an objective species, $Q_{\text {ex }}$ is considered to be preferable for high accuracy and precision, since both $Q_{\text {ex }}$ and $U$ can be measured more accurately and precisely than $I_{1}$ and $f$. Therefore, the accuracy and precision of the coulometric determination were evaluated by using $\varepsilon$ that was calculated based on $Q_{\text {ex }}$ precisely measured with a coulometer and $U$ precisely determined by weighing the solution with the aid of a balance (Fig. S1).

The effect of the number of GC fibers stuffed in a Teflon tube, $N_{\text {fiber }}$, on the accuracy and precision of the coulometric determination with the developed S-CE was investigated by using an S-CE with GC fibers of an $N_{\text {fiber }}$ between 500 and 4000. The electrolysis was carried out for $20 \mathrm{~min}$ by applying an $E$ of $+0.20 \mathrm{~V}$ versus SSE (curve 2 in Fig. 2) and forcing a solution containing $5 \times 10^{-4} \mathrm{M} \mathrm{Fe}^{3+}$ and $1 \mathrm{M} \mathrm{H}_{2} \mathrm{SO}_{4}$ to flow at an $f$ value of $0.2 \mathrm{~mL} \mathrm{~min}^{-1}$. The $Q_{\mathrm{ex}}$ and $\varepsilon$ obtained by 5 repeated 
Table 1 Effect of the concentration of $\mathrm{Fe}^{3+}, c_{\mathrm{Fe}^{3+}}$, on the coulomb number, $Q_{\mathrm{ex}}$, and electrolysis efficiency, $\varepsilon$, for the reduction of various concentration of $\mathrm{Fe}^{3+}, c_{\mathrm{Fe}^{3+}}$, in $1 \mathrm{M} \mathrm{H}_{2} \mathrm{SO}_{4}$ observed by the homogeneous solution flow method

\begin{tabular}{cccr}
\hline$c_{\mathrm{Fe}^{3+}} \mathrm{a} / 10^{-4} \mathrm{M}$ & \multicolumn{1}{c}{$f / \mathrm{mL} \min ^{-1}$} & $Q_{\mathrm{ex}} / 10^{-3}$ coulomb & \multicolumn{1}{c}{$\varepsilon, \%$} \\
\hline 0.05 & $0.2137 \pm 0.0004$ & $2.112 \pm 0.023$ & $101.9 \pm 1.1$ \\
0.5 & $0.2198 \pm 0.0004$ & $21.27 \pm 0.04$ & $99.7 \pm 0.2$ \\
1 & $0.2101 \pm 0.0004$ & $40.71 \pm 0.06$ & $99.8 \pm 0.1$ \\
5 & $0.2163 \pm 0.0003$ & $209.5 \pm 0.2$ & $99.8 \pm 0.1$ \\
10 & $0.2056 \pm 0.0003$ & $389.1 \pm 1.1$ & $97.5 \pm 0.3$ \\
\hline
\end{tabular}

a. Prepared by using a stock solution of $0.1 \mathrm{M}$ (factor, $f=1.006$ ) $\mathrm{Fe}^{3+}$. Electrolysis was performed for $20 \mathrm{~min}$ at $E=+0.20 \mathrm{~V}$ versus SSE. $f$, about $0.2 \mathrm{~mL} \mathrm{~min}^{-1} ; l, 50 \mathrm{~mm} ; f, Q_{\mathrm{ex}}$, and $\varepsilon$ were obtained through 5 repeated measurements.

measurements $(n=5)$ indicated that an $\varepsilon$ higher than $99 \%$ could be attained when more than $3500 \mathrm{GC}$ fibers were used as the working electrode of $l=50 \mathrm{~mm}$ (Table S1).

The $\varepsilon$ depends on the staying time of the sample solution at the surface of the working electrode, $t_{\text {stay }}$, which is controlled by $f$ and $l$. Therefore, the effects of $f$ and $l$ on $Q_{\text {ex }}$ and $\varepsilon$ were investigated by using an S-CE with working electrodes of various $l$ composed of $4000 \mathrm{GC}$ fibers and forcing a solution of $5 \times 10^{-4} \mathrm{M} \mathrm{Fe}^{3+}$ to flow at various $f$. The $Q_{\mathrm{ex}}$ and $\varepsilon(n=5)$ observed are listed in Table S2. The results indicate that quantitative electrolysis at an S-CE of $l=20$ or $50 \mathrm{~mm}$ can be attained with an $\varepsilon$ higher than $99.8 \%$ when $f$ is slower than about 0.1 or $0.3 \mathrm{~mL} \mathrm{~min}^{-1}$, respectively. In this connection, $t_{\text {stay }}$ was measured experimentally to be 12.4 or $12.1 \mathrm{~s}$ when $f$ and $l$ were $0.11 \mathrm{~mL} \mathrm{~min}^{-1}$ and $20 \mathrm{~mm}$ or $0.28 \mathrm{~mL} \mathrm{~min}^{-1}$ and $50 \mathrm{~mm}$, respectively. The $\varepsilon$ value obtained by electrolysis at $E=+0.20 \mathrm{~V}$ versus SSE decreased with increasing $f$. For example, $\varepsilon$ obtained at the S-CE of $l=50 \mathrm{~mm}$ and $f=0.5 \mathrm{~mL} \mathrm{~min}^{-1}$ was $99.1 \pm$ $0.3 \%$. One of the reasons for the decrease in $\varepsilon$ is attributable to a shift of $E_{1 / 2}$ and the slope of the $I-E$ curve with an increase of $f .{ }^{10}$ That is, $+0.20 \mathrm{~V}$ applied as $E$ was not sufficiently negative to attain quantitative electrolysis when $f$ was fast (Fig. 3).

The effect of $c_{\mathrm{Fe}^{3+}}$ on $\varepsilon$ for the coulometric determination of $\mathrm{Fe}^{3+}$ by an S-CE with a working electrode of $l=50 \mathrm{~mm}$ composed of $4000 \mathrm{GC}$ fibers was investigated based upon $Q_{\mathrm{ex}}$ and $\varepsilon$ observed by forcing solutions containing $\mathrm{Fe}^{3+}$ of various $c_{\mathrm{Fe}^{3+}}$ to flow at $f=$ about $0.2 \mathrm{~mL} \mathrm{~min}{ }^{-1}$ (Table 1). When $c_{\mathrm{Fe}^{3+}}$ was in the range between $5 \times 10^{-5}$ and $5 \times 10^{-4} \mathrm{M}$, the accurate and precise coulometric determination could be attained with $\varepsilon$ between 99.7 and $99.8 \%$ and standard deviations less than $0.2 \%$. Even when $c_{\mathrm{Fe}^{3+}}$ was very dilute, such as $5 \times 10^{-6} \mathrm{M}$, coulometric determination could be attained with a fairly $\operatorname{good} \varepsilon$, such as $101.9 \pm 1.1 \%$

\section{Coulometric determination of $\mathrm{Fe}^{3+}$ by flow injection method}

The feasibility of the developed S-CE as a detector in flow injection analysis was investigated by injecting a constant volume $(54.75 \pm 0.01 \mu \mathrm{L})$ of a sample solution containing $10^{-6}$ to $10^{-3} \mathrm{M} \mathrm{Fe}^{3+}$ and $1 \mathrm{M} \mathrm{H}_{2} \mathrm{SO}_{4}$ into the stream of a solution $(f=$ $0.2 \mathrm{~mL} \mathrm{~min}^{-1}$ ) containing only $1 \mathrm{M} \mathrm{H}_{2} \mathrm{SO}_{4}$. The electrolysis was carried out at $E=+0.20 \mathrm{~V}$ versus SSE. The peak current, $I_{\mathrm{p}}$, was almost proportional to $c_{\mathrm{Fe}^{3+}}$ in the range between $5 \times 10^{-6}$ and $5 \times 10^{-4} \mathrm{M}$ (Fig. S2).

The $\varepsilon$ in flow-injection method, $\varepsilon_{\mathrm{fi}}$, was also investigated by comparing $Q$ under the peak current, $Q_{\mathrm{p}}$, with a theoretical value of $Q_{\mathrm{p}}, Q_{\mathrm{tp}}$, for the reduction of the $\mathrm{Fe}^{3+}$ injected,

$$
\begin{aligned}
\varepsilon_{\mathrm{fi}} & =100\left(Q_{\mathrm{p}} / Q_{\mathrm{pt}}\right) \\
& =100\left(Q_{\mathrm{p}} / F c_{\mathrm{Fe}^{3+}} U_{\mathrm{fi}}\right),
\end{aligned}
$$

where $U_{\mathrm{fi}}$ is the volume of the sample solution injected.

The $\varepsilon_{\mathrm{fi}}$ values between 99 and $101 \%$ with precisions better than $2 \%(n=5)$ were observed when $c_{\mathrm{Fe}^{3+}}$ were between $5 \times$ $10^{-5}$ and $5 \times 10^{-4} \mathrm{M}$. The $\varepsilon_{\mathrm{fi}}$ values were $101.6 \pm 6.2$ and $92.8 \pm$ $6.1 \%$, when $c_{\mathrm{Fe}^{3+}}$ were $5 \times 10^{-6}$ and $5 \times 10^{-3} \mathrm{M}$, respectively (Table S3).

\section{Durability of the $S$-CE}

The developed S-CE could be continuously used for at least 1 week, as follows. The electrolysis of $\mathrm{Fe}^{3+}$ at an S-CE of $l=$ $50 \mathrm{~mm}$ was carried out for 1 week by forcing a solution containing $5 \times 10^{-4} \mathrm{M} \mathrm{Fe}^{3+}$ and $1 \mathrm{M} \mathrm{H}_{2} \mathrm{SO}_{4}$ to flow at $f=$

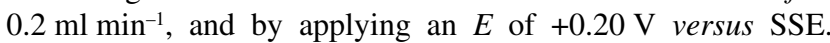
Then, $Q_{\text {ex }}$ for the electrolysis of the $\mathrm{Fe}^{3+}$ solution at $E=+0.20 \mathrm{~V}$ for $20 \mathrm{~min}$ was measured 5 times. The $\varepsilon$ value calculated using $Q_{\text {ex }}$ was identical $(99.8 \pm 0.2 \%)$ to the $\varepsilon$ which had been observed before the electrolysis for 1 week.

\section{Conclusion}

A column electrode of very simple structure and easy to prepare (i.e., S-CE) was proposed in the present work. The electrolytic behaviors observed at the S-CE were identical to those at the ordinary column electrode. The background current at the S-CE was small, since the surface area of the working electrode that did not participate in the electrolysis was minimized to the utmost in the S-CE. The coulometric determination of $\mathrm{Fe}^{3+}$ by the homogeneous solution flow method could be performed at the S-CE with an accuracy of $99.7 \%$ and the standard deviation of $0.2 \%(n=5)$, even when $c_{\mathrm{Fe}^{3+}}$ was as low as $5 \times 10^{-5} \mathrm{M}$, which had not been attained by using an ordinary thin-layer cell or column electrode. The S-CE was also applicable to a coulometric detection in flow-injection analysis with fairly good accuracy and precision.

Finally, it should be stressed that the coulometric determination in the present work was carried out by using $Q_{\text {ex }}$ and $U$ instead of $I_{1}$ and $f$, and it was demonstrated that the very accurate and precise determination could be attained by using $Q_{\mathrm{ex}}$ and $U$.

\section{Acknowledgements}

This work was partially supported by grants from Research for Promoting Technological Seeds of the Japan Science and Technology Agency and from the High-Tech Research Center Program for Private Universities from the Japan Ministry of Education, Culture, Sports, Science, and Technology

\section{Supporting Information}

Figures S1 and S2 and Tables S1-S3 are available free of charge on the Web at http://www.jsac.or.jp/analsci/.

\section{References}

1. J. J. Lingane, “Electroanalytical Chemistry”, 2nd ed., 1958, Chap. 19, Interscience, New York, 450.

2. J. E. Harrar, Trends Anal. Chem., 1987, 6, 152. 
3. A. J. Bard and L. R. Faulkner, "Electrochemical Methods. Fundamentals and Applications", 2001, John Wiley and Sons, New York, Chichester, Brisbane, Toronto, 417.

4. A. J. Bard, Anal. Chem., 1963, 35, 1125.

5. S. Uchiyama, M. Ono, and S. Suzuki, Anal. Chem., 1988, 60, 1835.

6. K. Štulík and V. Pacáková, J. Electroanal. Chem., 1981, 129, 1.

7. D.-I. Vaireanu, N. Ruck, and P. R. Fielden, Anal. Chim. Acta, 1995, 306, 115.

8. J. Lankelma and H. Poppe, J. Chromatogr., 1976, 125, 375.

9. B. Hagiwara, K. Kogoh, M. Saito, S. Shiraishi, T. Hashimoto, K. Tagawa, and H. Wada, J. Chromatogr., 1983, 281, 59.

10. T. Fujinaga and S. Kihara, Crit. Rev. Anal. Chem., 1977, 6, 223 , and references cited therein.
11. W. J. Blaedel, Anal. Chem., 1964, 36, 1245.

12. Y. Takata, Rev. Polarog., 2008, 54, 69.

13. R. E. Sioda, J. Electroanal. Chem., 1968, 13, 375.

14. S. Kihara, J. Electroanal. Chem., 1973, 45, 31.

15. Y. Takata, M. Taki, M. Ito, and T. Murao, J. Chromatogr., 1985, 332, 117.

16. H. Aoyagi, Y. Kitatsuji, Z. Yoshida, and S. Kihara, Anal. Chim. Acta, 2005, 538, 283.

17. J. Gerard, W. J. Holland, A. E. Veel, and J. Bozie, Mikrochim. Acta, 1969, 4, 724.

18. N. Tanaka and R. Tamamushi, Electrochim. Acta, 1964, 9, 963.

19. K. S.Stulík and V. Pacáková, "Electroanalytical Measurements in Flowing Liquids", 1987, Chap. 2, Wiley, New York, 27

20. Z. Galus and R. E. Adams, J. Phys. Chem., 1963, 67, 866. 